\title{
Acute Side Effects with High Dose Rate Computed Tomography-guided Three-dimensional Brachytherapy in Carcinoma Cervix
}

\author{
Sadia Sadiq ${ }^{1}$, Abubaker Shahid $^{1}$, Misbah Masood ${ }^{1}$, Rab Nawaz Maken $^{1}$, Amira Shami $^{1}$ and Ismat Fatima ${ }^{2}$ \\ ${ }^{1}$ Department of Radiotherapy, Institute of Nuclear Medicine and Oncology (INMOL), Lahore, Pakistan \\ ${ }^{2}$ Department of Clinical Pathology, Institute of Nuclear Medicine and Oncology (INMOL), Lahore, Pakistan
}

\begin{abstract}
:
Objectives: To determine the frequency and grades of acute side effects with three-dimensional brachytherapy in carcinoma cervix using RTOG/EORTC acute radiation morbidity scoring criteria.

Study Design: Descriptive study.

Place and Duration of Study: Department of Radiotherapy, Institute of Nuclear Medicine and Oncology (INMOL), Lahore, Pakistan from July 2016 to September 2017.

Methodology: A total of 55 histologically proven patients of squamous cell carcinoma of the cervix, aged between 16-70 years, were included. Patients with previous radiotherapy in pelvic area, inflammatory bowel diseases and known diabetics, were excluded. All patients were given a radiation dose of 7 Gray in 4 insertions through 3-dimensional conformal brachytherapy planning. Acute vaginal, gastrointestinal, and genitor-urinary side effects of brachytherapy were assessed.

Results: Mean age of the patient population was $47.09 \pm 13.10$ years (Range: 21-68). Mean time to presentation was 5.65 \pm 2.32 months and mean tumor size was $3.67 \pm 1.47 \mathrm{~cm}$. Majority, i.e. $18(32.7 \%)$ patient presented in stage III. Most of the patients, $26(47.3 \%)$, had ECOG-2 performance status. Grade-1 genitourinary toxicity was significantly high $(p<0.001)$. In lower gastrointestinal toxicity, Grade-1 was the highest being $54.5 \%$. Conversely, vaginal toxicities of grade- 2 and 3 were most commonly seen. Stratification of acute side effectswith respect toage, stage and tumor size revealed no significant association except in mucosal membrane toxicity, which was affected by tumor size $(p=0.004)$.

Conclusion: Three-dimensional brachytherapy in carcinoma cervix is a safe and tolerable procedure with minimal acute side effects.
\end{abstract}

Key Words: Cervical cancer, Brachytherapy, Acute toxicities, Computed tomography.

How to cite this article: Sadiq S, Shahid A, Masood M, Maken RN, Shami A, Fatima I. Acute Side Effects with High Dose Rate Computed Tomography-guided Three-dimensional Brachytherapy in Carcinoma Cervix. J Coll Physicians Surg Pak 2020; 30(06):638-642 https://doi.org/10.29271/jcpsp.2020.06.638.

\section{INTRODUCTION}

Cervical cancer is the 4 th most common cancer in women and the 7th overall in the world. ${ }^{1,2}$ The incidence in Pakistan has increased from $<9 / 100,000$ in 2002 to $13.6 / 100,000$ in 2008 (WHO statistics). The trends indicate that the country is moving from low to moderate risk level. ${ }^{3}$ Pakistan ranks $7^{\text {th }}$ among countries with the highest number of cervical cancer deaths worldwide, where 20 women die of cervical cancer daily. Patient survival and treatment depends upon staging at diagnosis. $^{4}$

Correspondence to: Dr. Ismat Fatima, Department of Clinical Pathology, Institute of Nuclear Medicine and Oncology (INMOL), Lahore, Pakistan

E-mail:drismatfatima14@gmail.com

Received: June 13, 2019; Revised: September 04, 2019;

Accepted: October 14, 2019

DOI: https://doi.org/10.29271/jcpsp.2020.06.638
The standard treatment for locally advanced cervical cancer is EBRT with concomitant cisplatin chemotherapy, followed by brachytherapy (BT). Compared to traditional X-ray-based brachytherapy that relies on point doses, the use of computed tomography (CT) and magnetic resonance imaging (MRI) for 3D planning of gynecologic brachytherapy provides a much more accurate volume-based calculation of dose to an imagedefined tumor and to the bladder, rectum, sigmoid, and other pelvic organs at risk (OAR) for radiation complications. The publication of standardised guidelines and an online contouring teaching atlas for performing 3D image-guided brachytherapy (IGBT) has created a universal platform for communication and training. This has resulted in a uniform approach to use IGBT for treatment; and an internationally accepted format for reporting clinical outcomes. Significant improvements in survival and reductions in toxicity are reported with the addition of image guidance to increase dose to tumor and decrease dose to the critical OARs. ${ }^{5-7}$

Although MRI-based IGBT is an attractive option with the poten- 
tial to improve disease control and minimise late treatment toxicity, it relies on repeated MRIs done during treatment. For many radiation departments, routine use of $\mathrm{MRI}$ at each brachytherapy fraction is not feasible due to cost and inaccessibility. Hence, a few groups have adopted a hybrid CT-based IGBT technique. ${ }^{8}$

After literature review, a study describing separately the grades of acute side effects with CT-based 3-D brachytherapy could not be found. So, a pilot study was conducted on 10 patients treated at INMOL for carcinoma cervix. Grade 0-4 vaginitis was found in 0/0/60/20/20\% patients, respectively. Grade 0-4 lower GIT side effects were observed in 30/40/20/10/0\% and Grade 0-4 Genitourinary (GU) side effects were experienced by $0 / 80 / 20 / 0 / 0 \%$ patients, respectively.

Most radiotherapy centres in Pakistan are performing 2-D brachytherapy. The lack of CT simulation facility and expertise remain the main barriers in initiation of 3-D brachytherapy.

The present study was planned with the intent to facilitate the delivery of safer technique to the patients. The colleagues all over the country will be motivated to make efforts to shift to 3-D brachy therapy for safer and better treatment of cervical cancer patients, if the results show reduced side effects.

The objective of the study was to estimate the grades (severity) of acute side effects with 3-D brachytherapy in carcinoma cervix using RTOG/EORTC acute radiation morbidity scoring criteria and the possible role of age, stage, and tumor size in grades of acute toxicities.

\section{METHODOLOGY}

The present descriptive case series was conducted in the Department of Radiotherapy, Institute of Nuclear Medicine and Oncology (INMOL), Lahore, from July 2016 to September 2017. Sample size of 55 cases was calculated with $95 \%$ confidence level, $8 \%$ margin of error, and taking expected percentage of Grade 3 gastrointestinal toxicity, i.e.10\% (least among all acute side effects) with 3-D brachy-therapy in carcinoma cervix.

Females (16-70 years) with histologically proven SCC of cervix FIGO stage IB2 to IVA were included. The patients received EBRT using 2-D technique up to a dose of $45 \mathrm{~Gy} / 25$ fractions with/without parametrial boost of $15 \mathrm{~Gy} / 8$ fractions with concurrent weekly cisplatin.

Patients receiving previous radiotherapy in pelvic area, $\mathrm{H} / \mathrm{O}$ inflammatory bowel disease (increases gastrointestinal toxicity) and fistula (rectal, urinary) presence of simultaneous malignancies and known diabetic patients for 10 years were excluded. Non-probability, consecutive sampling was done. Patients with ECOG 3 due to hydronephrosis and deranged renal function tests (RFT) were managed with percutanous nephrostomy and their RFT's and performance status were improved. They were then treated with CCRT.
Acute side effects were defined according to RTOG/EORTC criteria. These included those adverse events (deviation and change in normal function) that occurred from day 1 through day 90 after commencement of radiation therapy. Genitourinary toxicity Grade 0-4, including urination frequency, urgency, nocturia and hematuria, was recorded. Lower GIT toxicity, included change in bowel habits, abdominal pain, diarrhea, blood discharge, obstruction, fistula and tenesmus, was also noted. Vaginal toxicity (mucous membrane), including mild pain, vaginal mucositis, ulceration and hemorrhage, was also recorded.

After taking approval from CPSP and INMOL Ethical Review Committee, all cervical carcinoma patients, referred for chemoradiation fulfilling inclusion/exclusion criteria, were enrolled after written informed consent. Careful evaluation and staging was done with bi-manual pelvic examination, pervaginal examination, per rectal examination, chest X-ray, ultrasound abdomen, and MRI of pelvis.

Cancer staging was done according to AJCC (2010) staging system. All patients got a radiation dose of 7 Gray/4 insertions through 3-D conformal brachytherapy planning. Acute brachytherapy side effects were assessed 90 days after treatment with history and examination. Data were collected through medical record/radiotherapy charts and analysed through SPSS version 20. Descriptive statistics were used to summarise data. Mean \pm SD wascalculated for quantitative variables (age, tumour size, and disease duration). Frequency/percentages were calculated for qualitative variables including toxicity grades.

Data were binned for the variables including age, tumor size, and time to presentation for comparison. Chi-square test was applied for categorical variables. The dose received by AORs was within tolerance limit. D2cc of bladder was below $90 \mathrm{~Gy}$ and D2cc of rectum was below $75 \mathrm{~Gy}$.

Stratification of outcome variable (frequencies of acute toxicity) with pre-treatment radiological tumor size, stage at diagnosis and performance status was done to control the effect modifiers.

The association of acute toxicity with different variables was studied using Chi-square test. P-value of $\leq 0.05$ was considered significant.

\section{RESULTS}

Mean age of patient population was $47.09 \pm 13.10$ years (range: 21-68). Overall, $33(60.0 \%)$ patients were $>40$ years while 22 $(40.0 \%)$ were below 40 years of age. Mean time to presentation was $5.65 \pm 2.32$ months (1.0-11.0). Thirty-four (61.8\%) patients presented within 6 months of onset of symptoms while 21 (38.2\%) presented after 6 months of symptoms manifestation. Mean tumor size was $3.67 \pm 1.47 \mathrm{~cm}(1.0-6.0)$. Evaluation of stage distribution showed that majority 15 (27.3\%) presented in stage IVA. ECOG-2 was common performance status, i.e. 26 (47.3\%). 
Table I: Grade of acute toxicities in patients under study.

\begin{tabular}{|c|c|c|c|c|c|c|}
\hline Acute toxicities & $\begin{array}{c}\text { G-0 } \\
\text { n (\%) }\end{array}$ & $\begin{array}{c}\text { G-1 } \\
\text { n (\%) }\end{array}$ & $\begin{array}{c}\text { G-2 } \\
\text { n (\%) }\end{array}$ & $\begin{array}{c}\text { G-3 } \\
\text { n (\%) }\end{array}$ & $\begin{array}{l}\text { G-4 } \\
\text { n (\%) }\end{array}$ & p-value \\
\hline Genitourinary toxicity & $1(1.8)$ & $43(78.2)$ & $9(16.4)$ & $2(3.6)$ & 0 & $<0.001$ \\
\hline Lower gastrointestinal toxicity & $21(38.2)$ & $30(54.5)$ & $3(5.5)$ & $1(1.8)$ & 0 & $<0.001$ \\
\hline Vaginal toxicity (mucous membrane) & $1(1.8)$ & $4(7.3)$ & $29(52.7)$ & $16(29.1)$ & $5(9.1)$ & $<0.001$ \\
\hline
\end{tabular}

Table II: Grade of acute toxicities with respect to age, tumor size and stage.

\begin{tabular}{|c|c|c|c|c|c|c|c|}
\hline Acute toxicity & Groups-wise stratification & $\begin{array}{c}\text { G-0 } \\
\text { n (\%) }\end{array}$ & $\begin{array}{c}\text { G-1 } \\
\text { n (\%) }\end{array}$ & $\begin{array}{c}\text { G-2 } \\
\text { n (\%) }\end{array}$ & $\begin{array}{c}\text { G-3 } \\
\text { n (\%) }\end{array}$ & $\begin{array}{c}\text { G-4 } \\
\text { n (\%) }\end{array}$ & p-value \\
\hline \multirow{9}{*}{$\begin{array}{l}\text { Genitourinary } \\
\text { toxicity }\end{array}$} & \multicolumn{7}{|l|}{ Age groups } \\
\hline & $\leq 40$ years $(n=22)$ & $0(0)$ & $18(81.8)$ & $3(13.6)$ & $1(4.5)$ & $0(0)$ & \multirow[b]{2}{*}{0.806} \\
\hline & $>40$ years $(n=33)$ & $1(3.0)$ & $25(75.8)$ & $6(18.2)$ & $1(3.0)$ & $0(0)$ & \\
\hline & \multicolumn{7}{|l|}{ Tumor size } \\
\hline & $\leq 3.0 \mathrm{~cm}(\mathrm{n}=24)$ & $1(4.2)$ & $17(70.8)$ & $4(16.7)$ & $2(8.3)$ & $0(0)$ & \multirow[b]{2}{*}{0.244} \\
\hline & $>3.0 \mathrm{~cm}(\mathrm{n}=31)$ & $0(0)$ & $26(83.9)$ & $5(16.1)$ & $0(0)$ & $0(0)$ & \\
\hline & \multicolumn{7}{|l|}{ Stage } \\
\hline & $I-I I(n=22)$ & $1(4.5)$ & $16(72.7)$ & $4(18.2)$ & $1(4.5)$ & $0(0)$ & \multirow[b]{2}{*}{0.616} \\
\hline & III-IV (n=33) & $0(0)$ & $27(81.8)$ & $5(15.2)$ & $1(3.0)$ & $0(0)$ & \\
\hline \multirow{9}{*}{$\begin{array}{l}\text { Lower } \\
\text { gastrointestinal } \\
\text { toxicity }\end{array}$} & \multicolumn{7}{|l|}{ Age groups } \\
\hline & $\leq 40$ years $(n=22)$ & $10(45.5)$ & $11(50.0)$ & $1(4.5)$ & $0(0)$ & $0(0)$ & \multirow[t]{2}{*}{0.713} \\
\hline & $>40$ years $(n=33)$ & $11(33.3)$ & $19(57.6)$ & $2(6.1)$ & $1(3.0)$ & $0(0)$ & \\
\hline & \multicolumn{7}{|l|}{ Tumor size } \\
\hline & $\leq 3.0 \mathrm{~cm}(\mathrm{n}=24)$ & $7(29.2)$ & $13(54.2)$ & $3(12.5)$ & $1(4.2)$ & $0(0)$ & \multirow[t]{2}{*}{0.108} \\
\hline & $>3.0 \mathrm{~cm}(\mathrm{n}=31)$ & $14(45.2)$ & $17(54.8)$ & $0(0)$ & $0(0)$ & $0(0)$ & \\
\hline & \multicolumn{7}{|l|}{ Stage } \\
\hline & $I-I I(n=22)$ & $7(31.8)$ & $13(59.1)$ & $2(9.1)$ & $0(0)$ & $0(0)$ & \multirow[b]{2}{*}{0.555} \\
\hline & III-IV (n=33) & $14(42.4)$ & $17(51.5)$ & $1(3.0)$ & $1(3.0)$ & $0(0)$ & \\
\hline \multirow{9}{*}{$\begin{array}{l}\text { Vaginal toxicity } \\
\text { (mucous } \\
\text { membrane) }\end{array}$} & \multicolumn{7}{|l|}{ Age groups } \\
\hline & $\leq 40$ years $(n=22)$ & $1(4.5)$ & $0(0)$ & $12(54.5)$ & $7(31.8)$ & $2(9.1)$ & \multirow[t]{2}{*}{0.369} \\
\hline & $>40$ years $(n=33)$ & $0(0)$ & $4(12.1)$ & $17(51.5)$ & $9(27.3)$ & $3(9.1)$ & \\
\hline & \multicolumn{7}{|l|}{ Tumor size } \\
\hline & $\leq 3.0 \mathrm{~cm}(\mathrm{n}=24)$ & $1(4.2)$ & $1(4.2)$ & $8(33.3)$ & $13(54.2)$ & $1(4.2)$ & \multirow[b]{2}{*}{0.004} \\
\hline & $>3.0 \mathrm{~cm}(\mathrm{n}=31)$ & $0(0)$ & $3(9.7)$ & $21(67.7)$ & $3(9.7)$ & $4(12.9)$ & \\
\hline & \multicolumn{7}{|l|}{ Stage } \\
\hline & $I-I I(n=22)$ & $1(4.5)$ & $2(9.1)$ & $8(36.4)$ & $10(45.5)$ & $1(4.5)$ & \multirow[t]{2}{*}{0.102} \\
\hline & III-IV (n=33) & $0(0)$ & $2(6.1)$ & $21(63.6)$ & $6(18.2)$ & $4(12.1)$ & \\
\hline
\end{tabular}

Acute toxicities including GU, lower GIT, and vaginal toxicities were measured. Grade-1 genitourinary toxicity was most common, i.e. 43 (78.2\%) followed by Grade-II i.e. 9 (16.2\%), Table I. In lower GIT toxicity, Grade-1 was the highest being $30(54.5 \%, p<0.001)$ followed by Grade-0 toxicity which was observed in 21 (38.2\%) patients (Table I).

Conversely, vaginal toxicities of Grade-2 and 3 were commonly seen i.e.29 (52.7\%) and 16 (29.1\%), respectively. Grade-4 toxicity was also administered in 5 (9.1\%) patients. Four (7.3\%) patients had Grade-1 while 1 (1.8\%) experienced grade- 0 toxicity. Distribution of vaginal toxicities was also significantly different $(\mathrm{P}<0.001)$ with highest toxicity grade being Grade-2 (Table I).

Stratification of grades of acute side effects with respect to age groups revealed that age was not significantly related with severity of acute toxicities. In patients with age $\leq 40$ years ( $n=22), G-1$ GU toxicity was commonly seen, i.e. in 18
(81.8\%) patients. In patients aged $>40$ years $(n=33)$, Grade- 1 was also the most commonly observed toxicity in 25 (75.8\%) patients (Table II). No significant difference was observed in GU, lower GIT and vaginal toxicities with respect to age (Table II).

Tumor size also had no significant effect on GU and lower GIT toxicities ( $P=0.244$ and 0.108 , respectively). Contrarily, the grades of vaginal toxicities were significantly different in the patients with $\leq 3.0$ and $>3.0 \mathrm{~cm}$ tumor size $(p=0.004)$. Patients having tumor size $\leq 3.0 \mathrm{~cm}(n=24)$ had grade- 0 and G-1 toxicity in $1(4.2 \%)$ patient each. Grade-2 toxicity was recorded in $8(33.3 \%)$ and G-3 in $13(54.2 \%)$ patients. Only one patient had G-4 toxicity in this group. On the other hand, in the patients with $>3.0 \mathrm{~cm}$ tumor size $(n=31), \mathrm{G}-0$ toxicity was not seen and $4(12.9 \%)$ had G-4 toxicity. Patients with G-3 toxicity were, however, fewer in this group being 3 $(9.7 \%)$. In this patient group, the mostly common vaginal toxicity grade was G-2 with 21 (67.7\%) patients (Table II). 
Toxicity grades were not affected by disease stage (Table II).

\section{DISCUSSION}

MRI-based image-guided adaptive BT is a gold standard in cervical cancer treatment planning. However, CT is frequently being used for the purpose because MRI is not readily available in many institutes. In spite of the frequent use, there is scarcity of data relating the treatment outcomes, and especially acute non-hematological toxicities in CT-based 3-D brachytherapy of cervical cancer. The studies reported only chronic side effects. ${ }^{9}$ The present study was conducted to determine the acute side effects with 3-D B-T in carcinoma cervix, using RTOG/EORTC acute radiation morbidity scoring criteria.

Severe ( $\geq$ grade 3 ) GU and GIT acute toxicities were observed in only $2(3.6 \%)$ and $1(1.8 \%)$ patients, respectively (Table I and II). Acute severe $\mathrm{Gl}$ toxicities ( $\geq$ grade 3 ) are reported between 0 to $8 \%$ in literature and GU toxicities are found between 0 to $3 \% .{ }^{10,11}$ This study result is in concordance with literature showing minimal $\geq$ grade 3 toxicities. Grade 1 and 2 (mild toxicities) have not been described in literature, so a comparison could not be made. However, significantly high population had experienced only Grade-1 toxicities (both GI and GU). Grade-1 genitourinary toxicity was observed in 43 (78.2\%) and GIT in 30 (54.5\%) patients. Grade-2 GU and GIT toxicity was only in $9(16.4 \%)$ and $3(5.5 \%)$ patients, respectively. No Garde- 5 toxicity (mortality caused by toxicity) was seen in those patients.

Intracavitary BT applicator lies in close proximity to the vaginal mucosa exposing it to relatively high radiation dose. High grade vaginal toxicities have been reported in many studies. ${ }^{12-14}$ Here, G-3 mucosal toxicity was seen in 16 (29.1\%) and G-4 in 5 (9.1\%) patients.

No significant relation could be found with age, gender and tumor size in GU and GIT acute toxicities. Mucosal membrane toxicities were affected by tumor size in this study. Age and stage had no effect on these toxicities. The authors could not find some comparative studies giving the effects of these factors on acute toxicity grades.

The use of 3-D imaging for BT in cervical cancer ensures proper tumor coverage; and allows the evaluation of individual dose distributions applied to a certain volume, such as the high risk clinical target volume (HRCTV) and organs at risk. ${ }^{15-18}$ It was also observed that the 3-D brachytherapy is safe and effective in our population for the treatment of cervical cancer patients. Minimal acute side effects were observed in the organs at risk (OARs).

\section{CONCLUSION}

Three-dimensional brachytherapy in carcinoma cervix is a safe and tolerable procedure with minimal acute side effects. In institutions where CT simulation facility is avail- able, effort should be made to treat more patients with 3-D brachytherapy as compared to 2-D point-based brachytherapy.

\section{ETHICAL APPROVAL:}

Ethical approval for the study was obtained from CPSP and INMOL Ethical Review Committee prior to initiation of the research work.

\section{PATIENTS CONSENT:}

Patients were enrolled after written informed consent.

\section{AUTHOR CONTRIBUTION:}

SS: Data acquisition and analysis, interpretation, drafting and final approval.

ABS: Conception and design, interpretation, critical revision and final approval.

MM: Design, critical revision and final approval.

RNM, AS: Interpretation, critical revision and final approval.

IF: Analysis and interpretation, drafting and final approval.

\section{CONFLICT OF INTEREST:}

The authors declare no conflict of interest

\section{REFERENCES}

1. Bray F, Ferlay J, Soerjomataram I, Siegel RL, Torre LA, Jemal A. Global cancer statistics 2018 globoconestimates of incidence and mortality worldwide for 36 cancers in 185 countries. CA Clin J 2018; 68(6):394-424.

2. Wang JQ, Wang T, Shi F, Yang YY, Su J, Chai YL,et al. A randomized controlled trial comparing clinical outcomes and toxicity of lobaplatin versus cis platin-based concurrent chemotherapy plus radiotherapy and high-dose-rate brachytherapy for FIGO stage II and III cervical cancer.Asian Pac J Cancer Prev 2015; 16(14):5957-61.

3. Shahid M, Kazmi SU, Rehman A, Ainuddin J, Furqan S, Nazeer S. Cervical cancer screening and HPV genotype distribution among asymptomatic patients of Karachi Pakistan. PakJ Med Sci 2015; 31(3):493-8.

4. Parveen S, Sajjad R, Masood M, Usmani HA, Sadiq R, Yunus $N$. Cervical cancer outcome of treatment and causes of failure. J Pak Med Assoc 2006; 56(10):436-40.

5. Haie-Meder C, Pötter R, Van Limbergen E, Briot E, De Brabandere M, Dimopoulos J, et al. Recommendations from gynaecological (GYN) GEC ESTRO working group (I): concepts and terms in 3D image based 3D treatment planning in cervix cancer brachytherapy with emphasis on MRI assessment of GTV and CTV. Radiother Oncol 2005; 74(3):235-45.

6. Pötter R, Haie-Meder C, Van Limbergen E, Barillot I, De Brabandere M, Dimopoulos J, et al. Recommendations from gynaecological (GYN) GEC ESTRO working group (II): Concepts and terms in 3D image-based treatment planning in cervix cancer brachytherapy3D dose volume parameters and aspects of 3D image-based anatomy, radiation physics radiobiology. Radiother Oncol 2006; 78(1):67-77.

7. Viswanathan AN, Erickson BA.Seeing is saving: The benefit of $3 \mathrm{D}$ imaging in gynecologic brachytherapy. Gynecol Oncol 
2015; 138(1):207-15.

8. Simpson DR, Scandenbeg DJ, Carmona R, McMurtie RM, Enick J, Mell LK, et al. Clinical outcomes of computed tomography-based volumetric brachytherapy planning for cervical cancer, Int J Radiat Oncol Biol Phys 2015; 93(1): 150-7.

9. Dang MYZ, Li P, Li JP, Bai F, Zhang Y, Mu YF, et al. The efficacy and late toxicities of computed tomography-based brachytherapy with intracavitary and interstitial technique in advanced cervical cancer. J Cancer 2018; 9(9):1635-41.

10. Ntekim A, Adenipekun A, Akinlade B, Campbell O. High dose rate brachytherapy in the treatment of cervical cancer preliminary experience with cobalt 60 radionuclide source: A prospective study. Clin Med Insights Oncol 2010; 4:89-94.

11. Rakhsha A, Kashi ASY, Hoseini SM. Evaluation of survival and treatment toxicity with high-dose-rate brachytherapy with cobalt 60 in carcinoma of cervix. Iran J Cancer Prev 2015; 8(4):35-73.

12. YoshidaK, Yamazaki H, Nakamura S, Masui K, Kotsuma T, Akiyama $\mathrm{H}$, et al. Longitudinal analysis of late vaginal mucosal reactions after high-dose-rate brachytherapy in patients with gynecological cancer. Anticancer Res 2014; 34:4433-8.

13. Au SP, Grigsby PW. The irradiation tolerance dose of the proximal vagina. Radiother Oncol 2003; 67:77-85.

14. Hintz BL, Kagan AR, Chan P, Gilbert HA, Nussbaum H, Rao $A R$, et al. Radiation tolerance of the vaginal mucosa. Int J Radiat Oncol Biol Phys 1980; 6(6):711-6.

15. Fu ZZ, Li K, Peng Y, Zheng Y, Cao LY, Zhang YJ, et al. Efficacy and toxicity of different concurrent chemoradio-therapy regimens in the treatment of advanced cervical cancer a network meta-analysis. Medicine (Baltimore) 2017; 96(2):e5853.

16. Mazeron R, Gilmore J, Dumas I, Champoudry J, Goulart], Vanneste $B$, et al. Adaptive 3D image-guided brachytherapy a strong argument in the debate on systematic radical hysterectomy for locally advanced cervical cancer. Oncologist 2013; 18(4):415-22.

17. Petit A, Floquet A, Lasbareilles O, Stoeckle E, Chemin A, Kind $M$,et al. Pulsed-dose-rate brachytherapy for uterine cervix carcinoma 10 years of experience with 226 patients at a single institution. Brachytherapy 2013; 12(6):542-9.

18. Huang EY, Sun LM, Lin H, Lan JH, Chanchein CC, huang YJ, et al. A prospective cohort study to compare treatment results between 2 fractionation schedules of high-dose-rate intracavitary brachytherapy (HDR-ICBT) in patients with cervical cancer. Int J Radiat Oncol Biol Phys 2013; 85(1): 123-8. 